\title{
Endoscopic drainage using a lumen-apposing metal stent under contrast-enhanced harmonic endoscopic ultrasonography guidance
}

Endoscopic ultrasonography-guided transmural drainage (EUS-TMD) is an effective treatment for collections of infected peripancreatic fluid [1]. A novel one-step device consisting of a combined lumen-apposing metal stent (LAMS) and an electrocautery-enhanced delivery system (Hot AXIOS; Boston Scientific, Marlborough, Massachusetts, USA) was recently developed [2,3]. The stent flange interval is $10-\mathrm{mm}$ long; therefore, the recommended indication for this stent is a fluid collection with a wall of $<10 \mathrm{~mm}$. Evaluating the precise
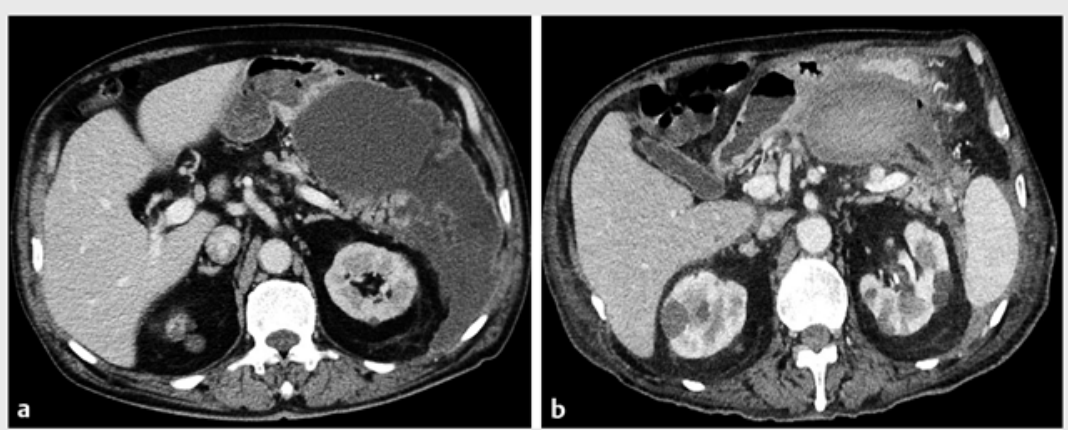

- Fig. 1 Computed tomography scan showing: a an area of infected walled-off necrosis caused by acute necrotizing pancreatitis; $\mathbf{b}$ an infected hematoma in the cavity of the previous walled-off necrosis, which was found 20 days after embolization to control bleeding from a ruptured newly formed blood vessel, which had filled the cavity with blood after surgical necrosectomy.
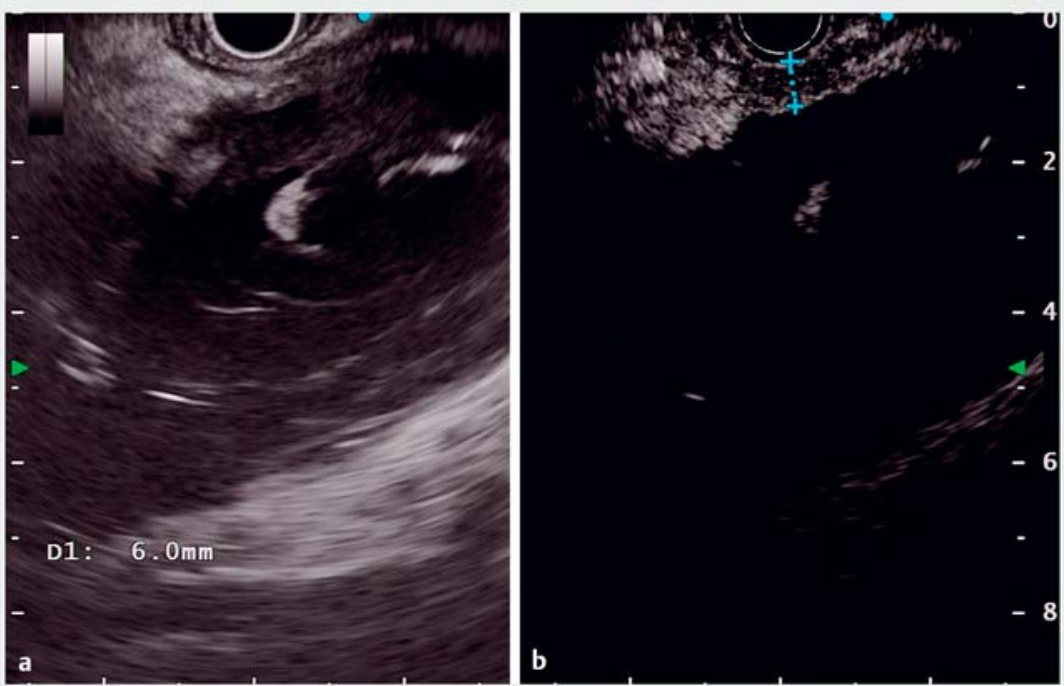

- Fig. 2 Endoscopic ultrasonography images of the infected hematoma showing: a on B-mode, a large number of blood clots that made it impossible to precisely determine the wall thickness; $\mathbf{b}$ after injection of sonographic contrast agent, the clearly defined cavity wall, allowing accurate measurement.

thickness of the cavity wall before this procedure is crucial, and a LAMS should not be used if the operator cannot be certain. Here, we report a case of successful drainage of an infected hematoma using the Hot AXIOS under contrastenhanced harmonic endoscopic ultrasonography (CH-EUS) guidance.

A 70-year-old man was diagnosed with infected walled-off necrosis (WON) caused by acute necrotizing pancreatitis ( Fig. 1 a). The infection was uncontrolled, even after multiple percutaneous and endoscopic drainage procedures. A step-up surgical necrosectomy [4] was performed and the infection was controlled temporarily; however, a newly formed blood vessel ruptured and the cavity where the WON had previously existed was filled with blood. Although the bleeding was controlled by vascular embolization, re-infection occurred 20 days after the procedure ( $\bullet \mathbf{F i g . 1} \mathbf{~ b}$ ).

We decided to perform EUS-TMD for the infected hematoma using the Hot AXIOS. However, the lesion contained a large number of blood clots and the wall thickness could not be precisely determined using only B-mode EUS imaging ( $\triangleright$ Fig. 2 a). Therefore, we scanned the lesion with $\mathrm{CH}$-EUS. Immediately after injecting a sonographic contrast agent, the contents

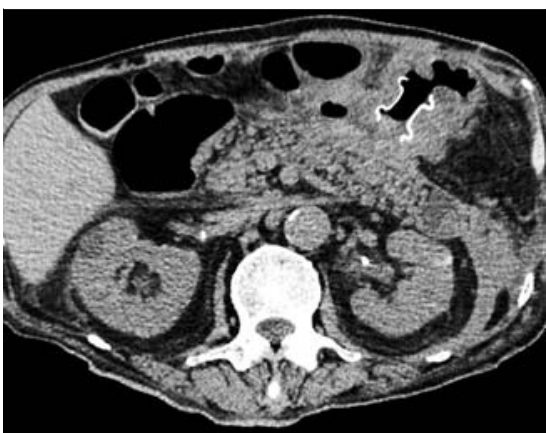

Fig. 3 Computed tomography scan after successful transgastric endoscopic ultrasound-guided infected hematoma drainage using a lumen-apposing metal stent. 


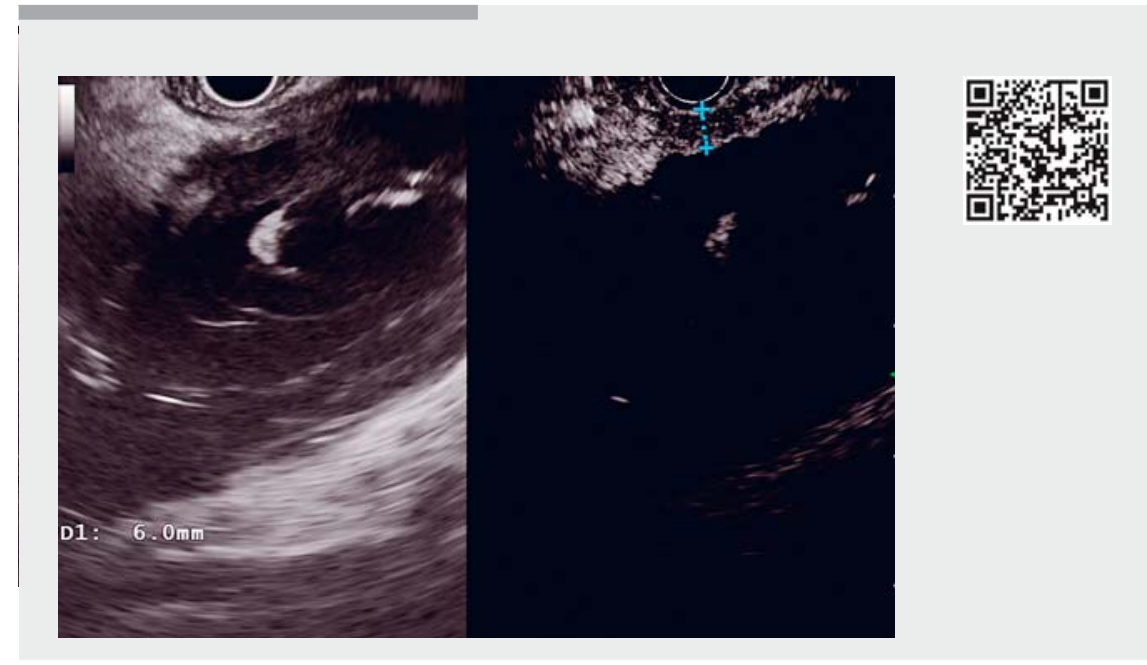

Video 1 Endoscopic ultrasonography-guided transluminal drainage of an infected hematoma using a lumen-apposing metal stent under contrast-enhanced harmonic endoscopic ultrasonography guidance.

were clearly identified as an avascular area, and the cavity wall was accurately detected ( Fig.2b). Subsequently, we punctured the lesion safely, which enabled proper deployment of the LAMS ( Fig. 3; Video 1 ).

These findings indicate that $\mathrm{CH}$-EUS could be a useful modality to clearly visualize target lesions in cases where the cavity wall cannot be precisely evaluated for standard EUS-TMD.

Endoscopy_UCTN_Code_TTT_1AS_2AC

Competing interests

None
The authors

Yasuki Hori, Michihiro Yoshida, Kazuki Hayashi, Itaru Naitoh, Akihisa Kato, Katsuyuki Miyabe, Hiromi Kataoka

Department of Gastroenterology and

Metabolism, Nagoya City University Graduate

School of Medical Sciences, Nagoya, Japan

\section{Corresponding author}

\section{Yasuki Hori, MD, PhD}

Department of Gastroenterology and Metabolism, Nagoya City University Graduate School of Medical Sciences, 1 Kawasumi, Mizuho-cho, Mizuho-ku, Nagoya 467-8601, Japan

Fax: +81-52-8520952

yhori@med.nagoya-cu.ac.jp

\section{References}

[1] Walter D, Will U, Sanchez-Yague A et al. A novel lumen-apposing metal stent for endoscopic ultrasound-guided drainage of pancreatic fluid collections: a prospective cohort study. Endoscopy 2015; 47: 63-67

[2] Teoh AY, Binmoeller KF, Lau JY. Single-step EUS-guided puncture and delivery of a lumen-apposing stent for gallbladder drainage using a novel cautery-tipped stent delivery system. Gastrointest Endosc 2014; 80: 1171

[3] Galasso D, Baron TH, Attili F et al. Endoscopic ultrasound-guided drainage and necrosectomy of walled-off pancreatic necrosis using a metal stent with an electrocautery-enhanced delivery system and hydrogen peroxide. Endoscopy 2015; 47 (Suppl. 01): E68

[4] van Santvoort HC, Besselink MG, Bakker O] et al. A step-up approach or open necrosectomy for necrotizing pancreatitis. NEJM 2010; 362: $1491-1502$

\section{Bibliography}

DOI https://doi.org/10.1055/a-0875-3546

Published online: 12.4.2019

Endoscopy 2019; 51: E187-E188

(c) Georg Thieme Verlag KG

Stuttgart · New York

ISSN 0013-726X

\section{ENDOSCOPY E-VIDEOS \\ https://eref.thieme.de/e-videos}

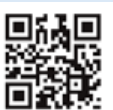

Endoscopy E-Videos is a free access online section, reporting on interesting cases and new techniques in gastroenterological endoscopy. All papers include a high quality video and all contributions are freely accessible online.

This section has its own submission website at

https://mc.manuscriptcentral.com/e-videos 